\title{
A comparison of pixel and object-based land cover classification: a case study of the Asmara region, Eritrea
}

\author{
Y. H. Araya ${ }^{1} \&$ C. Hergarten ${ }^{2}$ \\ ${ }^{I}$ Student of the Masters of Science in Geospatial Technologies, \\ Universidade Nova de Lisboa, Portugal \\ ${ }^{2}$ Centre for Development and Environment, Institute of Geography, \\ University of Berne, Switzerland
}

\begin{abstract}
In this paper we compare the performance of two image classification paradigms (object- and pixel-based) for creating a land cover map of Asmara, the capital of Eritrea and its surrounding areas using a Landsat ETM+ imagery acquired in January 2000. The image classification methods used were maximum likelihood for the pixel-based approach and Bhattacharyya distance for the object-oriented approach available in, respectively, ArcGIS and SPRING software packages. The advantages and limitations of both approaches are presented and discussed. The classification outputs were assessed using overall accuracy and Kappa indices. The pixel- and object-based classification methods result in an overall accuracy of $78 \%$ and $85 \%$, respectively. The Kappa coefficient for pixel- and object-based approaches was 0.74 and 0.82 , respectively. Although the pixelbased approach is the most commonly used method, assessment and visual interpretation of the results clearly reveal that the object-oriented approach has advantages for this specific case-study.

Keywords: Landsat ETM+, land cover, segmentation, pixel- and object-based classification, accuracy, Kappa coefficient.
\end{abstract}

\section{Introduction}

Multi-temporal mapping applying remote sensing and the Geographical Information System (GIS) are particularly useful for land use management and 
environmental studies. Historically, aerial photographs have been an important source of land use information (Bauer et al., [1]). In the last few decades, maps have been generated using traditional methods such as scanning and digitizing. Such techniques are still being used in many places e.g. Eritrea. In various papers (e.g. Kamagata et al., [7]) it is stated that traditional methods of mapping rely on visual interpretation of aerial photographs and follow-up field research. Mapping that uses such techniques is subject to some basic problems e.g. format transformation and rectification (analogue data are not easily processed). These and other related problems prompt many potential users to remain skeptical about the capabilities of remote sensing data (Rowlands and Lucas, [12]). Remote sensing data are more uniform than ancillary data, which vary in data format, accuracy, spatial resolution, and coordinate systems (Lu and Weng, [9]). Land cover mapping has evolved from using aerial photographs to being derived from digital remote sensor data (Caetano et al., [3]). Recent advances in computer assisted image classification and interpretation assist effective mapping. Satellite images along with GIS tools are powerful instruments for these purposes. Hence, an integrated approach of GIS and remote sensing was applied for effective land cover mapping.

In various mapping projects, different classification methods (e.g. pixel, subpixel, per-field and object-oriented approaches) have been applied to classify satellite images. For a particular study, different classifiers tend to output different classification results for the same spatial unit rendering the choice of methods difficult.

As a consequence, often different algorithms are combined for best outputs. This paper attempts to develop a land cover map of Asmara and its surroundings applying two different methods so that comparative analysis of both pixel- and object-based classification can be carried out. For this particular purpose, the image was classified and analyzed using pixel-based and object-oriented classifiers implemented in ArcGIS and SPRING, respectively.

\section{Objectives}

The principal objective of this paper is to compare the pixel- and object-based classification methods using Landsat ETM+ acquired in January 2000 of Asmara and its surrounding areas.

The more specific objectives comprise the following:

- Comparison of the performance of pixel- and object-based approaches for classifying urban-peri-urban landscapes in a semi-arid context

- Investigations on an object-based approach applied to medium resolution satellite imagery

- Assessment of the performance of an innovative object-oriented classification algorithm implemented in a free software package (SPRING)

- Drawing of conclusions from comparing final classification accuracies 


\section{Study area}

The study area extends to Asmara, being the capital of Eritrea and its surrounding areas. The study area is located on the highlands of East Africa in general and in the central highland of the country in particular. The area is situated at $15^{\circ} 13^{\prime} 44^{\prime \prime}$ and $15^{\circ} 25^{\prime} 36^{\prime \prime}$ North and $38^{\circ} 44^{\prime} 33^{\prime \prime}$ and $39^{\circ} 00^{\prime} 53^{\prime \prime}$ East (Figure 1) and is located some $90 \mathrm{~km}$ inland at an average altitude between 2100 to 2400 meters.

The climate is moderate with a temperature that ranges from $0^{\circ} \mathrm{C}$ (winter night temperature) to $+27^{\circ} \mathrm{C}$ (summer day temperature). This area has experienced some remarkable land cover changes due to urban expansion, population pressure and the development of various economic activities particularly since the independence of the country in 1993. Hence, updated land cover mapping is essential for effective land and resources management in the area.

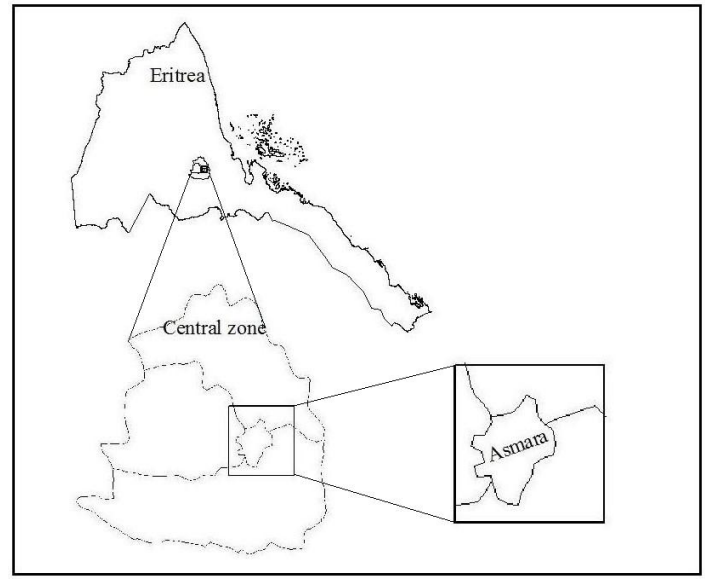

Figure 1: $\quad$ Study area.

\section{Data and methodology}

\subsection{Data}

Some of the considerations that must be taken into account when selecting imagery for land cover mapping is the required spectral and spatial characteristics, the date of acquisition and the preprocessing stage. The imagery used in this project is a Landsat ETM+ scene (WRS path 169, row 49) acquired in January 2000, a month that is generally cloud free for the study area. The resolution of the image is 30 meters. Other imagery data acquired by IKONOS and SPOT satellites covering the western part of study area as well as ASTER imagery were also used. Any data used in this study were projected into the global UTM projection system (UTM zone 37, WGS 84). 


\subsection{Methodology}

\subsubsection{Land cover classes}

The land cover classes applied in this project are adopted from the classification schemes adopted by the Ministry of Agriculture of Eritrea. The classification used by the ministry is based on the AFRICOVER land cover classification system. Considering the land cover diversities of the study area, the descriptions of the land cover classes were slightly adapted. Table 1 gives the land cover classes extracted in this project.

Table 1: $\quad$ Land cover classes.

\begin{tabular}{|c|c|l|l|}
\hline ID & LCID & \multicolumn{1}{|c|}{ Land cover } & \multicolumn{1}{|c|}{ Descriptions } \\
\hline 1 & BA-4 & Bare soil & Barren and rocky areas \\
\hline 2 & UR & $\begin{array}{l}\text { Urban and } \\
\text { associated areas }\end{array}$ & $\begin{array}{l}\text { Major urban areas and other impervious } \\
\text { surfaces }\end{array}$ \\
\hline 3 & FR-1 & Evergreen Forest & Evergreen forest and closed trees \\
\hline 4 & AG-3 & Irrigated fields & Irrigated lands and market gardening \\
\hline 5 & FR-7 & $\begin{array}{l}\text { Open or spares } \\
\text { shrubs }\end{array}$ & $\begin{array}{l}\text { Pasture lands and lands reserved for } \\
\text { different purposes }\end{array}$ \\
\hline 6 & AG-2 & Rainfed farming & $\begin{array}{l}\text { Agricultural farmlands including fallow } \\
\text { lands }\end{array}$ \\
\hline 7 & BA-3 & Rivers banks & $\begin{array}{l}\text { Grasses and wetlands along the banks of the } \\
\text { river }\end{array}$ \\
\hline 8 & AG-5 & Tree plantation & Tree plantation particularly Eucalyptus \\
\hline 9 & WB & Water bodies & Lakes and other water surfaces \\
\hline 10 & - & Shadow & $\begin{array}{l}\text { Shadow caused by the topography during } \\
\text { acquisition }\end{array}$ \\
\hline
\end{tabular}

\subsubsection{Image classifications}

Image classification is defined as the process of assigning pixels of continuous raster image to defined classes (Santos et al., [13]). It is a complex and time consuming process, which is affected by a wide variety of factors. To deal with that complexity, various classification methods have been developed, such as pixel-, sub-pixel-, fuzzy set and object-oriented approaches. Pixel-based methods are very often associated with the problem of mixed pixels, hampering the statistics based classifiers to assign the pixel to the appropriate categories. Object-oriented image classification methods provide a promising tool for mapping detailed land cover (Mori et al., [11]). These approaches consider group of pixels and geometric properties of image objects instead of relying only on spectral characteristics of a single pixel.

4.2.2.1 Pixel-based supervised image classification This approach relies on spectral differences between different surface features. Usually it is referred to as a parametric approach of classification since most classifiers (e.g. Maximum Likelihood) imply Gaussian distribution. In supervised classification, the analyst 
has to "train" the algorithm. Supervised classification algorithms include Maximum Likelihood, Minimum Distance, Parallelepiped, etc. In this paper, one of the standard decision rules, maximum likelihood was employed. Statistical properties of training data sets from ground reference data are used to estimate the probability density functions of the classes (Santos et al., [13]).

In this study, based on the analyst's prior knowledge and other resources (e.g. additional high resolution satellite imagery), 270 samples were collected. Signatures were then extracted from the training samples and applied to train the algorithm. Finally, a land cover classification map of the study area was generated using Maximum Likelihood classifier available in ArcGIS.

4.2.2.2 Object-oriented classification method The object-oriented method segments the imagery into homogenous regions based on neighbouring pixels' spectral and spatial properties. Unlike most other pattern recognition software tools operating at pixel level, object-oriented tools (e.g. SPRING and Definiens) first segment a multispectral image into homogeneous areas using segmentation algorithms. Although segmentation is not a new concept, classification using image segmentation has become increasingly significant in recent years (Blaschke, [2]). The segmentation process is based on "Region Growing" i.e. from sub-object into super object approach. According to Im et al., [5] the region growing algorithms start with smallest objects containing single pixels. In the process smaller objects are merged into larger objects based on scale, colour (spectral properties), and shape. The segmentation process stops when the smallest growth of an object exceeds a user-defined threshold. The greater the scale parameter, (i.e. similarity unit and pixel area), the larger is the size of the resultant objects. In this study a similarity unit of 12 and a pixel area of 15 were selected to create the segmented image. In addition, knowledge and resource based sample collection was carried out. Prior to classification, image enhancement in terms of histogram stretching was performed for better discrimination of land cover classes. 200 sample objects were collected using the spectral information of the objects. The Bhattacharyya distance classifier was then applied to produce the land cover map. The classification accuracy of the collected samples was assessed using a sample analysis tool implemented in SPRING. Finally, a membership function definition (mapping option) was applied to label the generated classes.

\section{Accuracy assessments}

Although accuracy assessment is important for traditional remote sensing techniques, with the advent of more advanced digital satellite remote sensing the necessity of performing an accuracy assessment has received new interest (Congalton, [4]). Currently, accuracy assessment is considered as an integral part of any image classification. Usually, accuracy assessment is performed with reference to some ancillary data such as aerial photographs, previously prepared maps and even high resolution satellite imagery or field checking. In this paper, the assessment is carried out using an IKONOS image acquired in 2000. In the 
literature, different accuracy assessment techniques are discussed. For example, cross tabulation and Kappa index are methods that are implemented by default in software packages like IDRISI. However, the most common approach to assess accuracy of remotely sensed data uses an error matrix and is referred to as confusion matrix. A confusion matrix is a square array of numbers set out in rows and columns, which expresses the relationship between the samples in the reference and the classified image. Using error matrix to represent accuracy is recommended and adopted as the standard reporting convention (Congalton, [4]). For this purpose, 500 samples were selected in ArcGIS using a random sample generator tool. The samples were then labeled into their respective classes and a confusion matrix was designed.

\section{Results and discussion}

The pixel and object-based classification images of the study area using landsat ETM+ are shown in figures 2 and 3, respectively. The following section addresses the result and analysis of the land cover map generated.

Various authors (e.g. Blaschke, [2]; Moeller et al., [10], Mori et al., [11], etc) have pointed out that object-based classification produces better land cover maps than does the pixel-based approach. Considering these facts, the paper attempted a comparative analysis of the classification method (pixel-based Maximum Likelihood and object-oriented Bhattacharyya method).

The final comparative analysis was carried out using the error matrix designed as well as Kappa coefficient derived for both approaches. Statistical measures of accuracy (e.g. producer's and user's accuracies) are presented in the

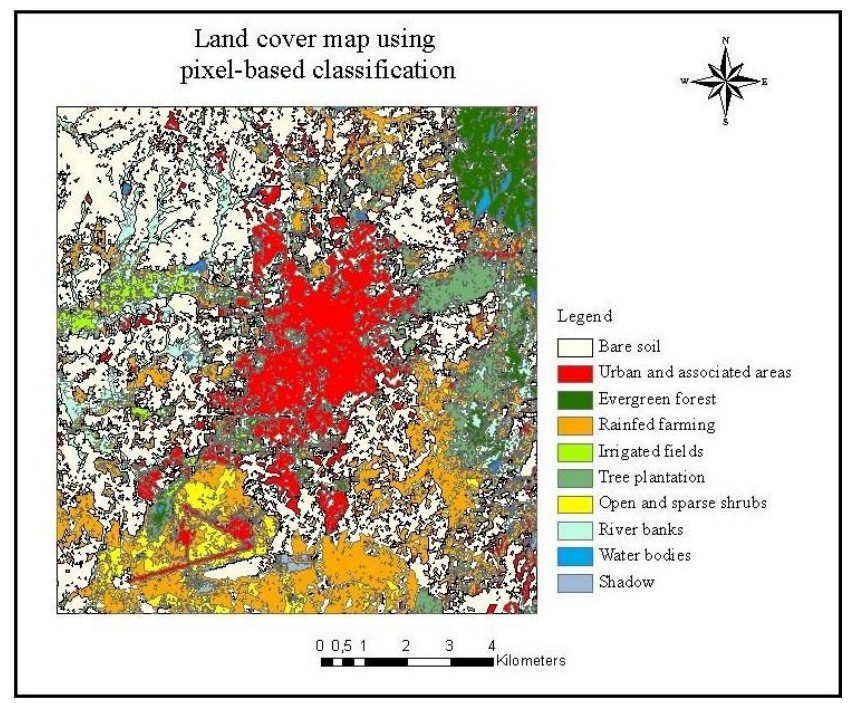

Figure 2: Land cover map using the pixel-based supervised classification method. 


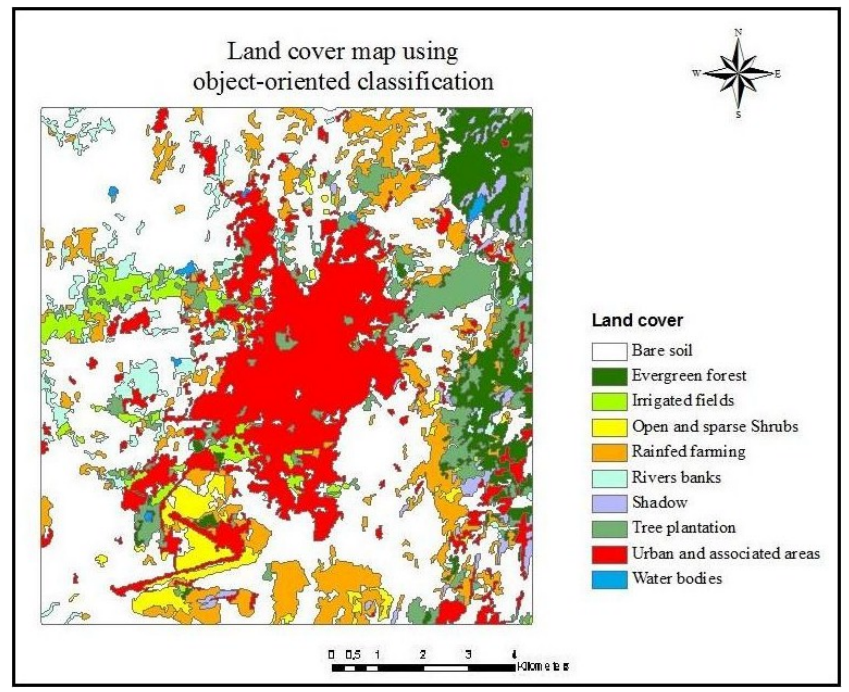

Figure 3: Land cover map using the object-oriented classification method.

tables 2 and 3 shown below. The overall accuracy and the Kappa coefficient are also calculated. The Kappa coefficient is calculated using the following formula given by Congalton, 1991:

$$
K=\frac{N \sum_{i=1}^{r} X \mathrm{ii}-\sum_{i=1}^{r}(X i+* X+1)}{N 2-\sum_{i=1}^{r}(X i+* X+1)},
$$

where $r$ is the number of rows in the matrix, $X_{\mathrm{ii}}$ is the number of observations in rows $\mathrm{i}$ and column $\mathrm{i}, \mathrm{Xi}+$ and $\mathrm{Xi}+1$ are the marginal totals of row $\mathrm{i}$ and column $\mathrm{i}$, respectively and $\mathrm{N}$ is the total number of observations.

The object-based classification produces an overall accuracy of $85.2 \%$ while the overall accuracy of the supervised classification was $78.7 \%$. Kappa coefficient is also calculated to be 0.82 and 0.74 for object and pixel-based classification, respectively. From user's accuracy point of view, farming land presented low accuracy in both maps. The class (farming) was, to some extent, misclassified as bare soil. This is probably caused by the season of the image acquisition. During the dry season it is expected that ploughed and harvested farm land would behave like bare soil. In addition, deep shadow is also misclassified as water because both have low reflectance in all bands. But it should be noted that water absorbs near infrared radiation, yet can reflect visible wavelength if it is muddy. It was also more reasonable to compare the results of the assessment from the producer's accuracy point of view. For the pixel-based approach, the highest producer's accuracy was $100 \%$ and $88 \%$ in the water 


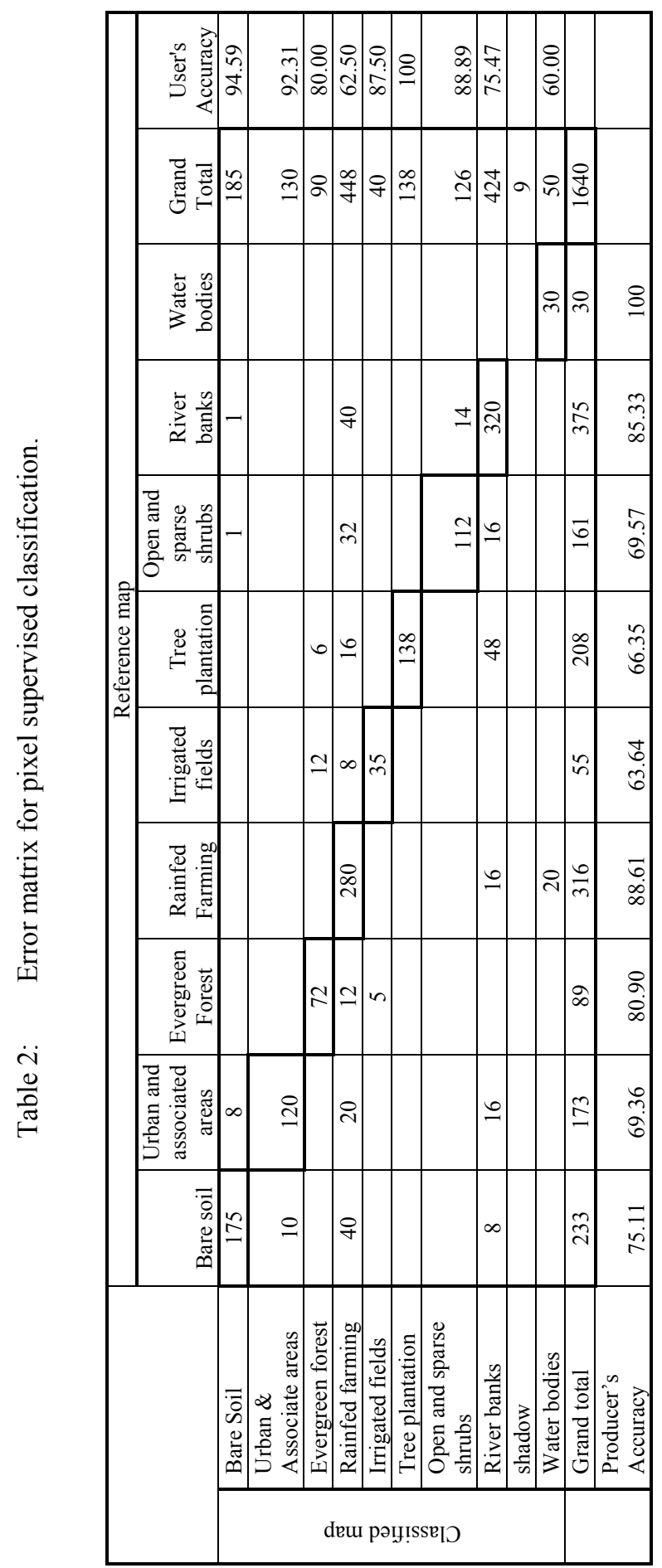


Geo-Environment and Landscape Evolution III 241

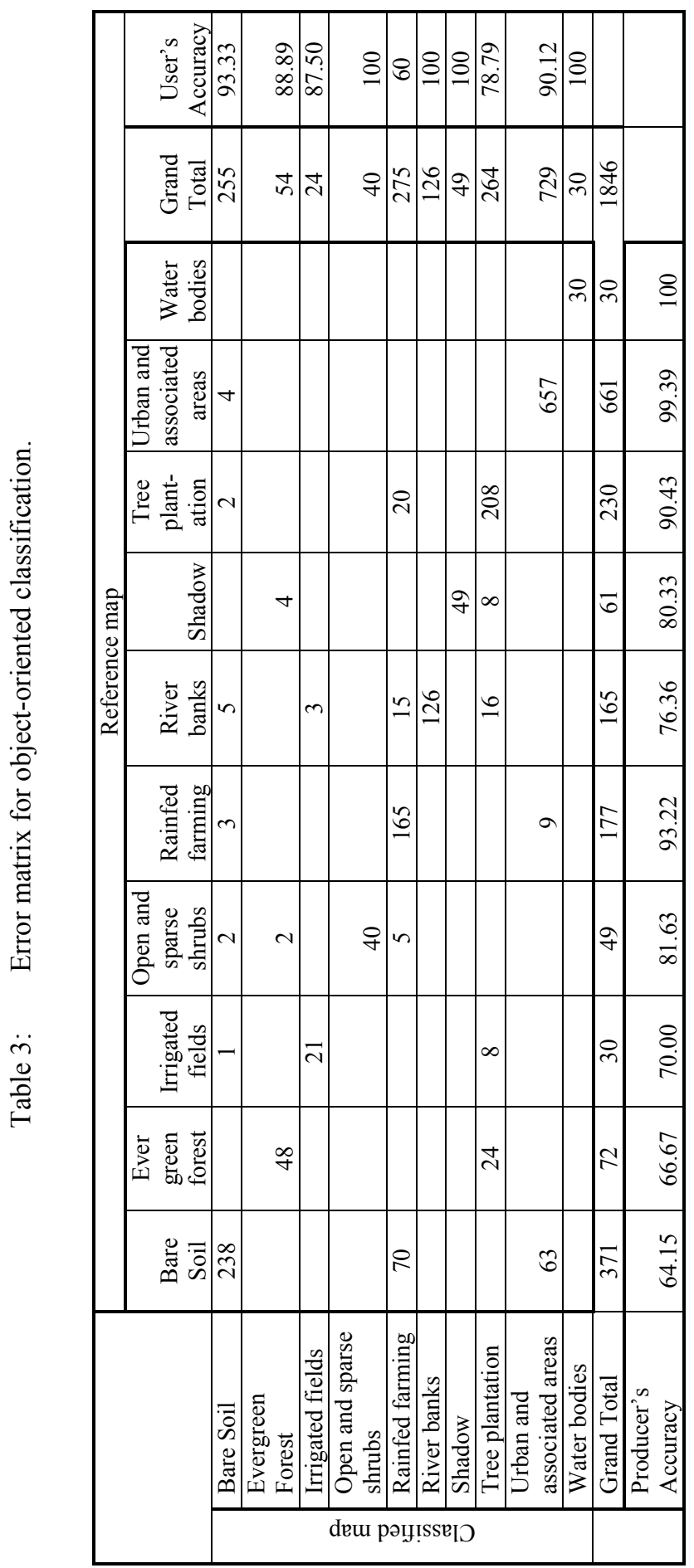


bodies and farming land. The lowest accuracy was $63.63 \%$ and $66.34 \%$ in the irrigated fields and tree plantation probably because of the high degree of signal saturation of active vegetation areas. On the other hand, the highest producer's accuracy for object-oriented method was $100 \%, 99 \%, 90 \%$ and $93 \%$ in water, urban areas, tree plantation and farming land, respectively. The lowest producer's accuracy for this method was $64 \%$ and $67 \%$ in bare soil and evergreen forest. Analysis of the results indicated that the object-based approach outperformed the pixel-based in terms of overall accuracy and Kappa coefficient.

\section{Conclusions}

In this project, an integrated approach of GIS and remote sensing was deployed. As stated, various classification algorithms are developed and applied in a multitude of researches. The paper addressed the performance of pixel- and object-based classification approaches for preparing land cover maps based on Landsat ETM+ acquired in 2000. For this purpose knowledge based (analyst experiences) and resource based (satellite imagery) were employed for collecting training samples. In addition, supervised classification algorithms like Maximum Likelihood and Bhattacharyya classifiers of pixel and object-based methods respectively were applied. Land cover maps of the study area were then generated. Since the paper was aiming at identifying suitable classification approaches, comparative studies of classification methods (pixel- and objectbased) were attempted. The comparative analysis was performed using the confusion matrix generated for both methods. Although the pixel-based approach is the traditionally most commonly used method, the results of the assessments (overall and producer's accuracy) and visual interpretation indicated that objectoriented procedure is advantageous for land cover mapping clearly outperforming the pixel-based approach. Therefore, the study concludes that the object-oriented procedure is the better classification approach for this study.

It remains to say the object-oriented algorithm implemented in SPRING deployed in this study proved to be a valid option compared to the state-of-theart application provided by Definiens; however there was no direct comparison carried out between the two programs within the scope of this study.

\section{Acknowledgements}

The paper was supported by the Centre for Development and Environment (CDE), University of Berne. We are much obliged to Dr. Steve Drury and Dr. Thomas Kohler for providing satellite data and their helpful reviews of this paper. The authors would also like to thank Dr. Pedro Cabral and Prof. Marco Painho for their assistance and cooperation.

\section{References}

[1] Bauer, M.E, Yuan, F. \& Saway, K.E., Multi-temporal Landsat image classification and change analysis of land cover in the Twin Cities 
(Minnesota) Metropolitan Area. Second int. workshop on the Analysis of multi-temporal remote sensing images, Italy, pp. 1-8, 2003.

[2] Blaschke, T., Towards a framework for change detection based on image objects. Remote sensing and GIS for Environmental Studies Gottinger Geographische Abhandlunger, pp. 1-9, 2005.

[3] Caetano, M., Santos, T., Freire, S., Nunes, A. and Carrao, H., Remote sensing and land cover mapping: Meeting User's Guides. http://www.igeo.pt/gdr/pdf/Caetano2001b.pdf 2001

[4] Congalton, R. G., A review of assessing the accuracy of classifications of remotely sensed data. Int. Journal of Remote sensing, 37, pp. 35-46, 1991.

[5] Im, J., Jensen, J. R \& Tulluis, J.A, Object-based change detection using correlation image analysis and image segmentation. Int. Journal of Remote sensing, pp. 1-25, 2007.

[6] Ivits, E., Hemphill, S., and Koch, B., Benchmarking of pixel and objectbased classification methods. http://portal.uni-freiburg.de/felis/data/ evapub/piobclas. 2005

[7] Kamagata, N., Hara, K., Mori, M., \& Akamatsu, Y., A new method of vegetation mapping by object-based classification using high resolution satellite. http://www.commission4.isprs.org/obia06/Papers/06_Automated \%20classification\%20LULC/OBIA2006_Kamagata_et_al.pdf. 2006

[8] Li, X., Ramachandran, R., Graves, S. and Movva, S., A hybrid objectbased/pixelbased classification approach to detect geophysical phenomena.

http://datamining.itsc.uah.edu/meeting06/papers/graves_uah.pdf. 2006

[9] Lu, D. \& Weng Q., A survey of image classification methods and techniques for improving classification performance. Int. Journal of Remote sensing, 28(5), pp. 823-870, 2007.

[10] Moeller, M.S, Stefanov, W.L. \& Netzband, M., Characterizing land cover changes in a rapidly growing metropolitan area using long term satellite imagery. Proc. of the ASPRS-70 years of service to the profession, Denver, Colorado, pp. 1-10, 2004.

[11] Mori, M., Hirose, Y., Akamatsu, Y. and Li, Y., Object-based classification of IKONOS data for rural land use mapping. http://www.isprs.org/istanbul2004/comm3/papers/305.pdf. 2004

[12] Rowlands, A.P. \& Lucas, R.M., Use of hyberspectral data for supporting the classification of agricultural land and semi-natural vegetation using multi-temporal satellite data. Proc. of the airborne imaging spectroscopy workshop, Bruges, pp. 1-5, 2004.

[13] Santos, T., Tenedorio, J., Encarnacao, S. \& Rocha, J., Comparison pixel vs. objectbased based classifiers for land cover mapping with EnvistaMeris data. 26th EARsel Symposium, Maio, Varsovia, pp. 1-9, 2006.

[14] Walter, V., Object-based classification of remote sensing data for change detection. Int. Journal of Remote sensing, 58, pp. 225-238, 2004. 